\title{
Arte engajada e transformação social: Hélio Oiticica e a exposição Nova Objetividade Brasileira
}

\section{Activist art and social change: Hélio Oiticica and the exhibition Nova Objetividade Brasileira}

Maria de Fátima Morethy Couto

"Da adversidade vivemos!" Assim escreve Hélio Oiticica, à guisa de conclusão, e em tom de revolta e de alerta, no texto de apresentação da exposição Nova Objetividade Brasileira, realizada no Museu de Arte Moderna do Rio de Janeiro em abril de 1967. A exposição contou com a participação de 40 artistas, entre os quais nomes emblemáticos da geração concretista e neoconcretista, como Lygia Clark, Lygia Pape, Willys de Castro, Hércules Barsotti e Ivan Serpa, e recém-ingressantes no mercado das artes, como Roberto Magalhães, Carlos Vergara, Carlos Zílio, Glauco Rodrigues, Antônio Dias, Rubens Gerchman e Pedro Escosteguy. A maioria absoluta das obras apresentadas era de caráter objetual e

\footnotetext{
Maria de Fátima Morethy Couto é doutora em História da Arte pela Universidade de Paris I - Panthéon /Sorbonne e professora de História da Arte do Departamento de Artes Plásticas do Instituto de Artes da Unicamp (fmorethy@uol.com.br).

Artigo recebido em 31 de dezembro de 2011 e aprovado para publicação em 12 de abril de 2012.
} 
colocava em questão os códigos artísticos e institucionais tradicionais, bem como criticava o poder efetivo de transformação social atribuído à arte abstrata, em especial às correntes construtivas, até o final dos anos 1950.

A mostra insere-se em um conjunto de exposições do período que buscavam promover o trabalho de artistas interessados em instituir um diálogo crítico com a realidade nacional, com a tensa situação política do país, e ao mesmo tempo pretendiam suscitar a integração entre prática artística e reflexão teórica por meio de debates e da publicação de textos diversos. Organizadas por uma rede específica de marchands, críticos e artistas, e realizadas em galerias e museus do Rio e de São Paulo entre 1964, ano da implantação da ditadura militar, e 1968, ano da decretação do AI-5, tais exposições provocavam a reflexão sobre os limites de atuação do artista e sobre o conceito de vanguarda válido para um país como o Brasil. Elas foram, segundo Paulo Reis, autor de uma tese sobre o tema, "a arena mais potente das idéias da vanguarda brasileira durante os anos $60,(.$.$) quebran-$ do as fronteiras da recepção da arte pelo público e sendo o palco, por excelência, das experimentações formais dos artistas" (Reis, 2005). Nesse sentido, podemos tomá-las como documentos passíveis de serem trabalhados pelo historiador e de serem submetidos a construções e interpretações teóricas de diversas ordens. Citemos algumas delas:

Em agosto de 1965, os marchands Jean Boghici e Ceres Franco montaram Opinião 65, no Museu de Arte Moderna do Rio de Janeiro. Dela participaram 30 artistas, alguns dos quais estrangeiros. Boghici era proprietário da Galeria Relevo, no Rio de Janeiro, e Ceres Franco residia então em Paris, onde atuava como crítica de arte. No ano anterior, ambos haviam organizado a mostra Novas Figurações da Escola de Paris, na citada galeria. Segundo Boghici, partiu dele a idéia de realizar uma nova exposição, agora em um museu, reunindo jovens artistas brasileiros e artistas atuantes em Paris. Seu título veio de um show de música popular, que ganhou reputação como um evento de protesto contra a ditadura militar, realizado em dezembro de 1964 no Rio de Janeiro e estrelado por Nara Leão, João do Vale e Zé Kéti. Na avaliação de muitos, Opinião 65 foi “a primeira resposta consistente, no plano da arte figurativa, seja ao informalismo, seja ao concretismo/neoconcretismo" em voga no Brasil (Morais, 1984). Para Antônio Dias, um de seus integrantes, "a mostra foi importantíssima para nós, sobretudo porque vimos que o que estávamos fazendo a nível de imagem não era uma coisa deslocada ou atrasada no tempo" (Morais, 1984).

Com efeito, também em nível internacional jovens artistas buscavam, desde o final dos anos 1950, romper com a separação entre arte e vida, característica da sensibilidade modernista. Nos Estados Unidos, artistas como Jasper Johns e Robert Rauschenberg promoveram o fim da "ditadura dos expressionistas abstratos" ao contestar os critérios de julgamento propostos pela crítica for- 
malista por meio de assemblages que diluíam as distinções entre pintura e escultura e atualizavam preceitos dos movimentos dadá e surrealista, sem jamais perder sua referência ao mundo "real". Criticavam, assim, tanto o individualismo heroico e a espontaneidade refinada dos pintores do expressionismo abstrato como a retórica de seus defensores, pautada na ideia de qualidade e de bom gosto da "melhor arte norte-americana de todos os tempos".

Na Europa, nesse mesmo período, os novos realistas também questionavam os valores da arte não figurativa, voltando seu olhar para o mundo urbano contemporâneo. Em 1960, por ocasião de uma mostra coletiva, o grupo, liderado pelo crítico Pierry Restany, lançou seu primeiro manifesto, no qual denunciou o "esgotamento e esclerosamento de todos os vocabulários estabelecidos, de todas as linguagens e estilos" e proclamou a necessidade de definir "as bases normativas de uma nova expressividade" (Restany, 1979: 144-145). Em oposição à subjetividade exacerbada da abstração lírica e da pintura informal, o manifesto propunha uma "tomada de consciência de um sentido comum da natureza moderna" e o resgate da "dimensão poética latente da realidade ambiental". Como contraponto ao gesto individualizado, sugeria a apropriação de fragmentos do real para fins poéticos; nessa concepção, caberia ao artista-inventor promover a transfiguração do banal em "obra de arte".

Foi em Opinião 65 que Oiticica apresentou pela primeira vez ao público seus Parangolés, com os quais solicitava a participação direta do espectador, que se transformava no próprio suporte da obra. Aqui, "a ação é a pura expressão da obra", e o vivencial e o processual são mais importantes que a realização de uma ideia. Chega-se então a "uma superação do objeto como fim da expressão estética" (Oiticica, 1986: 102). Com seus Parangolés, Oiticica provoca os limites institucionais e cria o único "incidente" da mostra, que entraria para a história, ao trazer para o vernissage passistas da Mangueira, os quais foram impedidos de entrar no museu. Conforme relata Rubens Gerchman,

Ninguém sabia se o Oiticica era gênio ou louco e, de repente, eu o vi e fiquei maravilhado. Ele entrou pelo museu adentro com o pessoal da Mangueira e fomos atrás. Quiseram expulsá-lo, ele responde com palavrões, gritando para todo mundo ouvir: é isso mesmo, crioulo não entra no MAM, isto é racismo. E foi ficando exaltado. Expulso, ele foi se apresentar nos jardins, trazendo consigo a multidão que se acotovelava entre os quadros. (Morais, 1984).

Em dezembro de 1965, Waldemar Cordeiro, que atuara como líder do grupo concreto paulista nos anos 1950, mas que, na época, já havia abandonado 
os princípios que norteavam aquele movimento, organizou em São Paulo, na Fundação Armando Álvares Penteado, uma mostra nos moldes de Opinião 65, que contou com a participação de 48 artistas atuantes no Brasil. Propostas 65 visava a fazer um inventário do "realismo atual do Brasil" não apenas por meio da apresentação de obras, mas também de sessões de debates com o público. O catálogo publicado na ocasião reuniu vários textos escritos por artistas e críticos, que versavam sobre temas como "Sobre a vanguarda", "Por que o feminismo", "No limiar de uma nova estética", "Propaganda: educação ou deseducação em massa", "Realismo ao nível da cultura de massa" e "Um novo realismo".

Este último texto, de autoria de Mário Schenberg, um dos maiores defensores de uma figuração de cunho social no país, discutia o interesse crescente dos artistas brasileiros pela utilização de "imagens habituais, estereotipadas, e por objetos de emprego corrente". Na opinião de Schenberg, as correntes abstracionistas desempenharam papel relevante na atualização da arte brasileira com as vanguardas internacionais, mas não lograram criar uma expressão artística efetivamente nacional:

Podemos hoje compreender que o abstracionismo, sobretudo em sua variante concretista, teve uma importância considerável para desembaraçar o movimento artístico brasileiro de formas anacrônicas do naturalismo e do realismo. Não serviu porém para ajudar a definir melhor a nossa fisionomia cultural, ao contrário do que ocorreu nos Estados Unidos com o expressionismo abstrato. Essa tarefa histórico-cultural ficou reservada para as novas formas de realismo, como indicam vários fatos. Aliás, mesmo nos Estados Unidos a pop art contribuiu mais do que o abstracionismo para caracterizar alguns aspectos essenciais da fisionomia cultural e social.

Arte de caráter participante, o chamado novo realismo, ao contrário das correntes abstratas, poderia tornar-se "um instrumento de conscientização nacional em todos os sentidos." (Cordeiro, 1965).

Também o artista Pedro Escosteguy, em seu texto "No limiar de uma nova estética", ressalta a importância de uma arte engajada, que escape da mera contemplação. Uma arte estritamente baseada em elementos estéticos, afirma Escosteguy, "não corresponde aos anseios coletivos (...) O artista que não se refugia em valores estéticos tradicionais, rechaçando a arte pela arte endereçada às minorias inoperantes, parte para uma semântica positiva de protesto e de denúncia" (Cordeiro, 1965). 
Nos dois anos subsequentes, o poder da nova figuração de cunho político-social, de caráter francamente experimental, consolida-se entre os integrantes da nova vanguarda brasileira, apesar de diversos pintores abstratos, em especial os defensores de uma arte marcada pelo gesto e por um contato direto com a tela, não mediado pela razão, seguirem suas carreiras, amparados por marchands, sem sofrer grandes abalos, obtendo premiações nacionais e internacionais em mostras do porte da Bienal de São Paulo e êxito junto ao público comprador.

De todo modo, se o debate artístico no Brasil dos anos 1950 procurou "afirmar a especificidade do fenômeno plástico-visual, a autonomia da forma em relação ao aspecto anedótico e/ou temático" (Morais, 1975: 80), na segunda metade dos anos 1960 novas questões passaram a inquietar os artistas da jovem vanguarda carioca e paulista, versando, em especial, sobre a função e responsabilidade social do artista. Ao findar a euforia desenvolvimentista que marcara os anos 1950 , percebe-se que a busca por uma linguagem plástica universal cedera lugar a um interesse por imagens de segundo grau e por temas locais e populares, relacionados à atualidade do país e ao cotidiano do cidadão comum. $\mathrm{O}$ advento do golpe militar certamente provocou, em um primeiro momento, uma radicalização do debate público, motivando artistas e intelectuais a tomarem posição em relação aos problemas políticos do país.

Desfeito o sonho de que o país pudesse ocupar um lugar privilegiado no concerto internacional de nações e acertar o passo com as nações mais desenvolvidas, desejava-se agora assumir a condição de subdesenvolvimento e fundar uma linguagem artística própria, condizente com essa situação. A referência a Mondrian e Malevitch, tão importante para a geração concreta/neoconcreta, não mais parecia fazer sentido para boa parte dos artistas jovens, que se mostravam mais interessados em estabelecer um contato direto e imediato com o público.

Nesse contexto, deve-se também ressaltar a adesão de antigos concretistas, como Maurício Nogueira Lima, Geraldo de Barros e o já citado Waldemar Cordeiro, aos propósitos do chamado "novo realismo". Em dezembro de 1964, Cordeiro apresentou seus popcretos (trabalhos de caráter tridimensional - quadro-objetos - construídos a partir de fragmentos de objetos do cotidiano e sucata), ao lado de alguns poemas visuais de Augusto de Campos, na galeria Atrium. No ano anterior, ele decretara o fim da "arte concreta histórica", lançando o conceito de arte concreta semântica, capaz "de abordar, no terreno da materialidade mais imediata e comum a problemática contingente dos acontecimentos sociais" (Wilder, 1982: 91).

Cabe lembrar que muito embora vivêssemos sob um regime ditatorial, ainda havia espaço para a contestação política, em especial no campo das artes, conforme comenta Roberto Schwarz em texto escrito na época (1970) e dedicado 
à relação entre cultura e política. Schwarz afirma que então, "apesar da ditadura da direita [havia] relativa hegemonia cultural da esquerda no país" e que sua produção "era de qualidade notável nalguns campos" (Schwarz, 1992: 62). São célebres, por exemplo, as peças contestatórias do Teatro de Arena e do Grupo Opinião apresentadas nesses anos e analisadas por Schwarz no artigo citado. Será a decretação do AI-5, em 1968, que provocará uma verdadeira fratura no cenário artístico e intelectual nacional, levando diversos opositores do regime à prisão ou ao exílio. Como também observa Otília Arantes a respeito do período 1965-1969, em artigo seminal sobre o tema, "boa parte dos artistas brasileiros pretendiam, ao fazer arte, estar fazendo política (...) [reclamando] para si um papel de ponta na resistência ao processo regressivo por que passava o país" (Arantes, 1983:5). Veremos que fazer política e engajar-se artisticamente não era equivalente a abraçar causas partidárias. "A arte era então concebida como um gesto ao mesmo tempo destruidor e criador a se desdobrar em todos os níveis", assinala Arantes no mesmo texto.

De modos distintos, questões do tipo morte da cultura, função da arte e do artista, nacionalismo e internacionalismo, expressão popular, subdesenvolvimento, entre outras, estarão presentes na obra de diversos artistas plásticos atuantes no período. Na leitura de Heloísa Buarque de Hollanda,

a produção cultural, largamente controlada pela esquerda, estará nesse período pré e pós-64 marcada pelos temas do debate político. Seja ao nível da produção em traços populistas, seja em relação às vanguardas, os temas da modernização, da democratização, o nacionalismo e a 'fé no povo' estarão no centro das discussões, informando e delineando a necessidade de uma arte participante, forjando o mito do alcance revolucionário da palavra poética (Hollanda, 1981: 17 e 37).

Entretanto, enquanto para alguns a tomada de posição frente aos problemas políticos do país poderia se dar sem prejuízo do experimentalismo formal, para outros a arte deveria atuar como meio de organização das massas, e a preocupação com o conteúdo deveria prevalecer sobre a pesquisa plástica. Com uma das facetas deste debate, lembremos, por exemplo, das idéias contidas no Anteprojeto do Manifesto do CPC, redigido por Carlos Estevam Martins em março de 1962. Nele, Martins forja a noção de uma arte popular revolucionária, priorizando o conteúdo sobre a forma e pregando que artistas e intelectuais deveriam assumir um lugar ao lado do povo na luta anti-imperialista.

Também Ferreira Gullar, antigo mentor do movimento neoconcreto, renegaria sua experiência vanguardista para atuar politicamente, junto ao CPC, 
em defesa da cultura popular e da participação do intelectual e do artista na luta pela autonomia do país. Passa então a clamar por uma arte a serviço do povo e dos interesses efetivos da nação. "Um conceito de 'vanguarda' estética, válido na Europa ou nos Estados Unidos”, questiona, "terá igual validez num país subdesenvolvido como o Brasil? As concepções de vanguarda artística transplantadas das nações desenvolvidas correspondem efetivamente a uma necessidade das sociedades subdesenvolvidas?" (Gullar, 1969: 63-64).

Contudo, é fundamental ressaltar que a ruptura com os valores e linguagens tradicionais e o abandono dos suportes artísticos convencionais também comportavam um sentido revolucionário e desafiador. A pintura de cavalete é posta em xeque por muitos integrantes dessa geração; em troca há uma crescente apropriação de objetos e símbolos do cotidiano e uma maior atração por materiais menos nobres, precários e de uso corrente. Em lugar da escultura tradicional, os chamados "objetos" e "caixas", realizados com materiais pouco nobres, invadem os salões e exposições alternativas do período, revelando a rejeição pelos artistas das atitudes exclusivamente formalistas e das posições esteticistas em favor "de vínculos imediatos com a existência ao redor" (Zanini, 1983: p. 73). Sobre esse tema, Daisy Peccinini assinala que

a maioria dos objetos desse período transmite uma posição crítica seja de ordem política e social, ou de negação dos valores estabelecidos tradicionalmente em relação à obra de arte, como criação estética e original. Na natureza dos objetos do período 1963 a 1968 reflete-se a desmistificação da obra de arte, quer pelo caráter tosco, inacabado e precário dos materiais usados, pela temática crítica e irreverente, quer pela frequente situação do espectador para que participe da obra, como coautor, rompendo com o isolamento da obra de arte tradicional, feita para ser contemplada (Peccinini, 1978:14).

Em 1966, duas novas versões das exposições anteriormente mencionadas foram organizadas, nos mesmos espaços institucionais: Opinião 66, no $\mathrm{Mu}$ seu de Arte Moderna do Rio de Janeiro, e Propostas 66, na Fundação Armando Álvares Penteado. Esta última mostra resumia agora a um fórum de discussões sobre o realismo nas artes, com a intervenção de críticos e artistas. Por meio da análise de temas como "Conceituação da arte nas condições históricas atuais do país", "Arte de vanguarda e organização da cultura no Brasil" e "Situação da vanguarda no Brasil", pretendia-se forjar a noção de uma vanguarda "tipicamente brasileira", politicamente engajada e atuante, comprometida com o tempo presente. 
Por ocasião do seminário "Situação da Vanguarda no Brasil", Rubens Gerchman se pronunciou sobre a importância do "objeto" na arte dos anos 1960, revelando a importância dessa discussão para o período (apud Peccinini, 1978: 147):

Acredito que o objeto para o artista contemporâneo deva ser seu meio de maior e melhor comunicação com o espectador. Os materiais industriais - plásticos, resinas - estão para a segunda metade do século XX como os 'óleos' para a Renascença. O objeto deve dar todo um sentido maior de informação para o espectador. Finalmente, o objeto está assumindo um aspecto totalmente novo, através de sua multiplicação - 'obra em série'. O objeto será a verdadeira expressão de nossa época. (...) Acredito que o objeto venha a desempenhar brevemente um grande fator cultural.

Hélio Oiticica é ainda mais incisivo, ao declarar, nessa mesma ocasião, que

O que há de realmente pioneiro na nossa vanguarda é essa nova fundação do objeto, advinda da descrença nos valores esteticistas do quadro de cavalete e da escultura, para a procura de uma arte ambiental (...) Essa magia do objeto, essa vontade incontida pela construção de novos objetos perceptivos (tácteis, visuais, proposicionais etc.), onde nada é excluído, desde a crítica social até a penetração de situações-limite, são características fundamentais de nossa vanguarda, que é vanguarda mesmo e não arremedo internacional de país subdesenvolvido, como até agora o pensa a maioria de nossas ilustres vacas de presépios da crítica podre e fedorenta. (Oiticica, 1986: 112)

Essa intenção de traçar o perfil da jovem vanguarda brasileira será reafirmada por Oiticica no texto que escreve para a citada mostra Nova Objetividade Brasileira ("Esquema Geral da Nova Objetividade"). Nele, Oiticica discorre sobre as "múltiplas tendências" vanguardistas então em curso no Rio de Janeiro e em São Paulo, procurando "agrupá-las culturalmente" e criando assim o que Paulo Reis chama de súmula de um programa de vanguarda da arte nacional comprometida com seu tempo. Na avaliação de Rodrigo Naves, esta foi uma das "primeiras intervenções teóricas desse tipo de um artista brasileiro" (Naves, 2002). Para outros autores, o texto será "seminal para a arte contemporânea, e não apenas a brasileira” (Freire, 2006: 20). 
Oiticica não almejava traçar um perfil rigoroso da jovem vanguarda brasileira nem tampouco lançar um novo movimento artístico. Interessado em ir além do conceito de novo realismo, empregado em 1965, como vimos, por Mário Schenberg, Oiticica cunha o termo Nova objetividade, a seu ver mais apto a descrever a tendência dominante no meio artístico experimental brasileiro de criar "novas ordens estruturais, não [mais] 'pintura' ou 'escultura', mas ordens ambientais, o que se poderia chamar de objeto" (Oiticica, 1986: 112). Todavia, Oiticica não considerava a nova objetividade um "movimento dogmático, esteticista, ou um novo ismo, tal qual os que proliferaram na arte da primeira metade do século XX", e sim um "estado típico da arte brasileira atual".

Embora entendesse que a "falta de unidade de pensamento [era] uma característica importante" do momento em que vivia, ele acreditava ser possível identificar os "pontos em comum" da nova arte brasileira para diferenciá-la das grandes correntes dominantes no plano internacional, em especial a pop, a op art, o nouveau réalisme e o minimalismo. Na realidade, aos olhos de muitos dos participantes desse debate, a nova arte brasileira já se apresentava como uma corrente artística de significação internacional, possuindo características singulares que a distinguiam dos movimentos internacionais. Em diversos textos e testemunhos publicados no período, percebe-se um desejo contundente de distinguir o que se fazia aqui no campo das artes do que se passava no exterior, em especial nos Estados Unidos. "A pop art americana, por exemplo, é mera constatação: constatam um hamburger, e daí?”, pergunta-se por exemplo Antônio Dias em entrevista concedida a Ferreira Gullar em 1966 (Gullar, 1967). De modo semelhante, Frederico Morais, um dos críticos mais atuantes nesse período, considera que, se na arte norte-americana prevalece uma "atitude cool (distante, fria, não participante)", no Brasil, ou na América Latina "a pop adquiriu um caráter hot” (Morais, 1975: 97).

Compartilhando desse espírito, Oiticica, em seu texto, elenca cinco características como as mais marcantes da produção da jovem vanguarda nacional, a saber: 1 . vontade construtiva geral; 2 . tendência para o objeto ao ser negado e superado o quadro de cavalete; 3 . participação do espectador (corporal, táctil, visual, semântica etc.); 4. abordagem e tomada de posição em relação a problemas políticos, sociais e éticos; 5 . tendência para proposições coletivas, e 6 . ressurgimento e novas formulações do conceito de antiarte.

É evidente que vários desses tópicos têm relação direta com os princípios que nortearam o movimento neoconcreto, do qual Hélio Oiticica participou ativamente na segunda metade dos anos 1950. Em diversas passagens de seu texto, Oiticica refere-se às experiências inovadoras do neoconcretismo, discutindo seu caráter inaugural e apontando seus desdobramentos no campo da arte contemporânea brasileira, campo este afetado pela implantação recente da ditadura 
militar no país. Para Paulo Reis, Oiticica constrói assim uma linearidade histórica entre o passado mais recente (anos 1950) e o momento atual (anos 1960), justificando a presença cada vez mais crescente do objeto na arte brasileira e a especificidade da participação do espectador. Todavia, como aponta Reis, "Oiticica não propôs um rompimento com sua trajetória anterior, o concretismo e o neoconcretismo, como fez Gullar, mas construiu uma tradição do debate artístico que tomou a movimentação construtiva como sua gênese" (Reis, 2005: 142).

É porém importante assinalar o quanto as indagações de Ferreira Gullar ainda atraíam a atenção de Oiticica. Em seu texto, Oiticica defende abertamente as proposições mais recentes do poeta maranhense, afirmando que "a obra e as ideias de Ferreira Gullar, no campo poético e teórico, foram as que mais [contribuíram] neste período no sentido de criar uma base sólida para uma cultura brasileira”. Compreendendo que a postura esteticista [tornara-se] insustentável em nosso panorama cultural, Oiticica considera que as idéias de Gullar "aparecem como um estímulo para os que veem no protesto e na completa reformulação político-social uma necessidade fundamental de nossa atualidade cultural":

O que Gullar chama de participação é, no fundo, essa necessidade de uma participação total do poeta, do intelectual em geral, nos acontecimentos e nos problemas do mundo. (...) Quer ele que não bastem à consciência do artista como homem atuante somente o poder criador e a inteligência, mas que o mesmo seja um ser social, criador não só de obras, mas modificador também de consciências (no sentido amplo, coletivo), que colabore ele nessa revolução transformadora, longa e penosa, mas que algum dia terá atingido o seu fim - que o artista 'participe' enfim da sua época e de seu povo (Oiticica, 1986: 94).

Ressalte-se no entanto que, embora Oiticica reconhecesse o papel da arte enquanto modificadora da realidade, jamais fez qualquer tipo de concessão didática ao público ou aderiu a um ativismo político direto, "estabelecendo com Gullar um diálogo no qual reinterpreta, segundo um ponto de vista inteiramente coerente com o processo de sua obra, as posições de 'arte engajada' de Ferreira Gullar" (Zílio, 1983: 32).

Como sabemos, jamais houve da parte de Oiticica qualquer intenção de submeter seu trabalho a ideais político-partidários. Por outro lado, creio que podemos afirmar que, do grupo neoconcreto, Oiticica foi um dos artistas mais preocupados, durante a década de 1960, em conferir à sua prática uma dimensão política capaz de interferir no tecido social. Entendia a arte por um viés utópico, 
considerando-a um meio eficiente de transformação do homem e da sociedade, capaz levar o indivíduo a tomar consciência de sua situação de "ser social inteiro". Em sua relação com o artístico, os indivíduos poderiam transformar-se em sujeitos de sua história.

Já Lygia Clark procurou manter-se distante do intenso debate sobre a necessidade de conversão do artista à militância. Em texto publicado no catálogo da mostra Opinião 66, intitulado "Nós recusamos", ela enfatizou o caráter singular de seu trabalho, calcado na participação cada vez mais intensa do espectador, questionando:

O que se passa a meu redor? Todo um grupo de homens vê claramente que a arte moderna não comunica e se torna cada vez mais um problema de elite. Então que se volte para a arte popular - esperando encher o fosso que os separa da maioria. Consequência: eles rompem os laços que os atavam ao desenvolvimento da arte universal e se rebaixam a uma expressão de caráter local. Eu vejo um outro grupo que sente lucidamente a grande crise da expressão moderna. Os que fazem parte disso procuram negar a arte, mas não acham nada mais para expressá-la do que exatamente obras de arte. Eu pertenço a um terceiro grupo que procura provocar a participação do público. Esta participação transforma totalmente o sentido da arte, como a entendemos até aqui. Isto porque: (...) num mundo em que o homem tornou-se estranho a seu trabalho, nós o incitamos, pela experiência, a tomar consciência da alienação em que vive (Clark, 1980: 30-31).

Oiticica, porém, ao reconhecer que ocorrera, a partir dos anos de 1964-65, um extravasamento das fronteiras artísticas para o domínio do político, considerava que todo artista deveria tomar consciência de seu papel social:

Há atualmente no Brasil a necessidade de tomada de posição em relação a problemas políticos, sociais e éticos, necessidade essa que se acentua a cada dia e pede uma formulação urgente, sendo o ponto crucial da própria abordagem dos problemas no campo criativo: artes plásticas, literatura, etc. (Oiticica, 1986: p. 94).

Oiticica acreditava ainda que o fenômeno da vanguarda no Brasil dos anos 1960 "não [era] mais uma questão de um grupo provindo de uma elite isolada, mas uma questão cultural ampla, de grande alçada, tendendo às soluções 
coletivas". De modo semelhante a Gullar, perguntava-se "como, num país subdesenvolvido, explicar o aparecimento de uma vanguarda e justificá-la, não como uma alienação sintomática, mas como um fator decisivo no seu progresso coletivo? Como situar aí a atividade do artista? O problema poderia ser enfrentado com uma outra pergunta: para quem faz o artista sua obra?" (Oiticica, 1986: 97).

Dentro desse espírito, mas contrariando aqueles que priorizavam o conteúdo sobre a experimentação, ele considerava fundamental retomar e defender novas formulações do conceito de antiarte, tema que discutira amplamente em texto datado de 1966, intitulado "Posição e Programa”. A seu ver, a relação do artista com o público deveria "dar-se em grande escala (...) com a proposição de obras não acabadas, abertas", capazes de introduzir o espectador no processo criador. Para tanto, não bastava apenas renegar a arte do passado, mas sim criar "novas condições experimentais", nas quais o artista assumisse "o papel de proposicionista, empresário ou mesmo educador".

Antiarte - compreensão e razão de ser o artista não mais como um criador para a contemplação, mas como um motivador para a criação - a criação como tal se completa pela participação dinâmica do espectador, agora considerado 'participador'. (...) Não há a proposição de um 'elevar o espectador a um nível de criação', a uma 'metarrealidade', ou de impor-lhe uma 'ideia' ou um 'padrão estético' correspondentes àqueles conceitos de arte, mas de dar-lhe uma simples oportunidade de participação para que ele 'ache' aí algo que queira realizar -é pois uma 'realização criativa' o que propõe o artista, realização esta isenta de premissas morais, intelectuais ou estéticas - a antiarte está isenta disto - é uma simples posição do homem nele mesmo e nas suas possibilidades criativas vitais (Oiticica, 1986: 77 e 79).

Um exemplo concreto de atualização desse pensamento é Tropicália, ambiente/instalação montado pela primeira vez na mostra Nova Objetividade Brasileira, e que consistia, na descrição de Frederico Morais, em "uma cabine ("penetrável) em meio a um cenário tropical, com plantas, araras, areia, brita, poemas enterrados e, no seu interior, raízes com cheiro forte, objetos de plástico etc. O espectador/participante percorria seu interior descalço, percurso que terminava diante de uma tv ligada" (Morais, 1975:95).

Como explica o próprio artista, Tropicália veio "diretamente dessa necessidade fundamental de caracterizar um estado brasileiro", de dar forma a uma vanguarda essencialmente nacional: 
Tropicália é a primeiríssima tentativa consciente, objetiva, de impor uma imagem obviamente brasileira ao contexto atual de vanguarda e das manifestações em geral da arte brasileira. (...) Tropicália (...) veio contribuir fortemente para essa objetivação de uma imagem brasileira total, para a derrubada do mito universalista da cultura brasileira, toda calcada na Europa e na América do Norte, num arianismo inadmissível aqui: na verdade, quis eu com a Tropicália criar o mito da miscigenação - somos negros, índios, brancos, tudo ao mesmo tempo (Oiticica, 1986: 107-108).

$\mathrm{Na}$ análise de Guy Brett, um dos primeiros críticos estrangeiros a se interessar pelo trabalho de Oiticica e a buscar promovê-lo no exterior, Tropicália "arrancou a imagem do pop de sua associação norte-americana com a cultura de consumo, situando-a em meio às aspirações e às diversidades da metrópole brasileira". Todavia, ela não deve ser considerada uma "obra do folclore brasileiro", apesar das imagens tropicais apresentadas de maneira explícita:

o nível oculto de Tropicália encontra-se no processo pelo qual se penetra nele, na teia de imagens sensoriais que produzem um confronto intensamente íntimo, em especial talvez com a mais íntima de todas as imagens: o universal aparelho de televisão ligado na mais completa escuridão (Brett, 2005: 38).

Brett busca com isso demonstrar o caráter universal da proposta de Oiticica, que visa à transformação do indivíduo e não apenas do homem brasileiro.

Também para Celso Favaretto, "o oculto da Tropicália é o mais manifesto: o modo de agenciamento das imagens, das linguagens, dos comportamentos".

Como manifestação ambiental, Tropicália não produz uma ideia totalizadora de Brasil (incompreensível, irracional, exuberante, absurdo, surreal): estilhaça essa representação. As raízes profundas sobem à superfície e são arrancadas no labirinto: o Brasil não se classifica como imagem. No labirinto, experimenta-se o ilimitado e a indeterminação, a transmutação como perda da identidade na construção de diferentes identidades (Favaretto, 1992: 140-141).

Entretanto, conforme ressalta o autor, ao conjugar experimentalismo e crítica, ao ir além da imagem enfatizando o "elemento vivencial direto", Tropicá- 
lia define uma linguagem de resistência à diluição. Nas palavras do próprio Oiticica publicadas no catálogo da mostra, "no Brasil, hoje, para se ter uma posição cultural atuante, que conte, tem-se que ser contra, visceralmente contra tudo o que seria em suma o conformismo cultural, político, ético, social” (Da adversidade vivemos!)

Em dezembro de 1968, o governo militar decretou o Ato Institucional $\mathrm{n}^{\mathrm{o}}$ 5, o qual outorgava ao presidente da República todos os poderes para fechar provisoriamente o Congresso, intervir nos estados e municípios, cassar mandatos e suspender direitos políticos, assim como demitir ou aposentar servidores públicos. Se em 1968 a segunda edição da Bienal de Artes Plásticas da Bahia foi fechada no dia seguinte à sua abertura, em 1969 a censura proibiu a realização da mostra dos artistas selecionados para a representação brasileira da IV Bienal de Paris, que aconteceria no MAM do Rio de Janeiro. Tal atitude provocou um boicote internacional à X Bienal de São Paulo, realizada no mesmo ano de 1969, organizado pelo crítico francês Pierre Restany e apoiado por artistas e intelectuais de diferentes nacionalidades. No início dos anos 1970, o experimentalismo defendido por Oiticica, em especial seu apelo para que o artista assumisse o papel de 'proposicionista' e o espectador se transformasse em participador, parecia sobreviver de modo tímido em manifestações de arte-na-rua, como os Domingos da Criação, que ocorriam apesar do controle e da censura da ditadura. Realizados em seis ocasiões distintas entre janeiro a agosto de 1971 (Um Domingo de Papel, ODomingo por um Fio, O Tecido do Domingo, Domingo Terra-a-Terra, O Som do Domingo e $O$ Corpo-a-corpo do Domingo), esses eventos promoviam o contato do público com os mais diversos materiais com o objetivo de exercitar sua criatividade. Como pressupostos teóricos, fundamentados livremente em alguns dos conceitos desenvolvidos por Oiticica, tais manifestações demonstravam, segundo seu propositor, Frederico Morais, que "o museu deve[ria] preocupar-se em trazer ao grande público o próprio ato criador", já que "em seu estado atual, a arte subs-ti tuiu a coisa [objeto] pela atividade, [sendo] o artista o autor de uma estrutura inicial, [cujo] viver ou desabrochar depende do nível de participação do público" (Morais, 1975: 105-106).

Cabe também ressaltar que durante esses mesmos anos algumas exposições e manifestações artísticas afrontaram censores e chocaram o público com a apresentação de trabalhos experimentais de forte conteúdo crítico, marcando época. Cite-se, por exemplo, o Salão da Bússola, realizado em 1969 no MAM/RJ, no qual o artista Antônio Manuel apresentou-se nu, e Do corpo à terra, evento que ocorreu no Parque Municipal de Belo Horizonte e durante o qual Artur Barrio "apresentou" suas trouxas ensanguentadas.

Todavia, o acirramento crescente da tensão política no contexto nacional obrigou muitos dos integrantes da vanguarda brasileira dos anos 1960, entre 
eles Lygia Clark, Ferreira Gullar e Mário Pedrosa, a escolherem o exílio. Hélio Oiticica deixou o país no final da década de 1960 para uma temporada de alguns meses em Londres e Brighton, convidado pela Sussex University. Em 1970, ganhou uma bolsa de estudos da Fundação Guggenheim e instalou-se em Nova York, retornando apenas em 1978 ao Brasil, onde veio a falecer em 1980, com 43 anos de idade. Terminava assim o sonho de um projeto coletivo de nação, de uma efetiva transformação social via arte.

\section{Referências bibliográficas}

AMARAL, Aracy. Arte e meio artístico: entre a feijoada e o $x$-burguer. São Paulo: Nobel, 1982.

ARANTES, Otília Beatriz Fiori. Depois das vanguardas. Arte em Revista, São Paulo, ano $5, \mathrm{n}^{\circ} 7$, agosto 1983 , p. 5-20.

BASBAUM, Ricardo (org.). Arte contemporânea brasileira. Texturas, dicções, ficções, estratégias. Rio de Janeiro: Rios Ambiciosos, 2001.

BRETT, Guy. Brasil experimental. Arte/vida: proposições e paradoxos. Rio de Janeiro: ContraCapa, 2005.

CLARK, Lygia. Lygia Clark. Rio de Janeiro: Funarte, 1980 (Catálogo de exposição).

COCCHIARALE, Fernando e GEIGER, Ana Bela. Abstracionismo geométrico e informal - a vanguarda brasileira nos anos cinqüenta. Rio de Janeiro: Funarte, 1987.

CORDEIRO, Waldemar. Propostas 65. Exposição e debates sobre aspectos do realismo atual do Brasil. São Paulo: Fundação Armando Álvares Penteado, dezembro 1965 (Catálogo de exposição).

COUTO, Maria de Fátima Morethy. Por uma vanguarda nacional: a crítica brasileira em busca de uma identidade artística (19401960). Campinas: Ed. Unicamp. 2004.

FAVARETTO, Celso. A invenção de Hélio Oiticica. São Paulo: Edusp, 1992.

FIGUEIREDO, Luciano. Lygia Clark. Hélio Oiticica. Cartas, 1964-1974. Rio de Janeiro: Editora UFRJ, 1996.

FREIRE, Cristina. Arte conceitual. Rio de Janeiro: Jorge Zahar, 2006.

GULLAR, Ferreira. Cultura posta em questão. Rio de Janeiro: Civilização Brasileira, 1965.

Entrevista de Antônio Dias e Rubens Gerchman a Ferreira Gullar. Revista Civilização Brasileira. Rio de Janeiro, ano 1, $\mathrm{n}^{\mathrm{o}} 11$ e 12 , dezembro 1966/março 1967, p. 170-180.

Vanguarda e subdesenvolvimento. Ensaios sobre arte. Rio de Janeiro: Civilização Brasileira, 1969.

(org.). Arte brasileira hoje: situação e perspectivas. Rio de Janeiro: Paz e Terra, 1973.

HOLLANDA, Heloísa Buarque de. Impressões de viagem - CPC, vanguarda e des- 
bunde: 1960/1970. São Paulo: Brasiliense, 1981.

MORAIS, Frederico. Artes plásticas: a crise da hora atual. Rio de Janeiro: Paz e Terra, 1975.

(org.). Ciclo de exposições sobre arte no Rio de faneiro: neoconcretismo/19591961. Rio de Janeiro: Galeria de arte BANERJ, setembro 1984. (Catálogo de exposição).

NAVES, Rodrigo. Um azar histórico: desencontros entre moderno e contemporâneo, Novos Estudos - Cebrap, São Paulo, $\mathrm{n}^{\circ}$ 64, novembro 2002, p. 5-21.

OITICICA, Hélio. Aspiro ao grande labirinto. Rio de Janeiro: Rocco, 1986.

PECCININI, Daisy. Objeto na arte. Brasil anos 60. São Paulo: Museu de Arte Brasileira da FAAP (Catálogo de exposição).

- Figurações. Brasil anos 60. São Paulo: Itaú Cultural e Edusp, 1999.

PEDROSA, Mário. Política das artes. São Paulo: Edusp, 1995.

- Forma e percepção estética. São Paulo: Edusp, 1995.

Edusp, 1998.

\author{
Edusp, 2000.
}

REIS, Paulo Roberto de Oliveira. Exposiçóes de arte - vanguarda e política entre os anos 1965 e 1970. Tese de doutorado em História. Universidade Federal do Paraná, Curitiba, 2005.

RESTANY, Pierre. Os novos realistas. São Paulo: Perspectiva, 1979.

SCHWARZ, Roberto, $O$ pai de família e outros ensaios. Rio de Janeiro: Paz e Terra, 1978.

SCHENBERG, Mário. Pensando a arte. São Paulo: Nova Stella, 1988.

WILDER, Gabriela S. Waldemar Cordeiro: pintor vanguardista, difusor, crítico de arte, teórico e líder do movimento concretista nas artes plásticas em São Paulo, na década de 50. Dissertação de mestrado em Artes. Escola de Comunicação e Artes da USP, São Paulo, 1982.

ZANINI, Walter. História geral da arte no Brasil. São Paulo: Instituto Moreira Salles, Fundação Djalma Guimarães, 1983.

ZÍLIO, Carlos et alii. O nacional e o popular na cultura brasileira. Artes plásticas e literatura. São Paulo: Brasiliense, 1983.

\section{Resumo}

$\mathrm{O}$ artigo pretende analisar os objetivos e a repercussão de uma das mais importantes exposições de vanguarda ocorridas na década de 1960:

a Nova Objetividade Brasileira, montada no Museu de Arte Moderna do Rio de Janeiro. Realizada um ano antes da promulgação do AI-5, a exposição demonstra a vitalidade do debate em curso sobre a possibilidade de criação "uma cultura tipicamente brasileira, com características e personalidade próprias".

Palavras-chave: Hélio Oiticica; arte de vanguarda; exposições de arte; Nova Objetividade Brasileira; arte figurativa; ditadura militar. 


\section{Abstract}

The article analyzes the aims and the impact of one of the most important avant-garde exhibitions held in the 1960's at the Museum of Modern Art in Rio de Janeiro: Nova Objetividade Brasileira. Carried out one year before the AI-5, this exhibition demonstrates the vitality of the ongoing debate about the possibility of creating "a typically Brazilian culture, with its own characteristics and personality."

Key words: Hélio Oiticica; Brazilian avant-garde art; art exhibitions; Nova Objetividade Brasileira; figurative art; military dictatorship.

\section{Résumé}

Larticle analyse les objectifs et l'impact de l'une des plus importantes expositions d'avant-garde qui a eu lieu dans les années 1960 au Musée d'Art Moderne de Rio de Janeiro: Nova Objetividade Brasileira. Organisée un an avant la promulgation de l'AI-5, l'exposition témoigne de la vitalité du débat en cours sur la possibilité de créer "une culture typiquement brésilienne, avec ses caractéristiques et sa personnalité propre".

Mots-clés: Hélio Oiticica; art brésilien d'avant-garde; expositions d'art; Nova Objetividade Brasileira; art figuratif; dictature militaire. 